\title{
TWO 'HOPELESS' UROLOGICAL CASES IN INFANTS*
}

\author{
BY \\ PIERRE BOISSONNAT \\ From Hôpital Necker-Enfants Malades, Paris, France
}

In paediatric surgery the prognosis is often difficult, and sometimes unpredictable. Cases considered to have a favourable prognosis may turn out to be fatal. Here are two urological cases at first thought hopeless but which had unexpectedly gratifying results after periods of seven and 19 years' follow-up.

\section{Case Reports}

Case 1. A boy was born after caesarean section tecause of dystocia due to enormous kidneys. When he was 4 days old he had passed no urine and urethral catheterization showed that the bladder was empty. Though blood urea was normal, urography showed no dye concentration. At cystoscopy two normal-looking ureteric orifices could not be catheterized. Polycystic kidneys at first seemed the most likely diagnosis but thorough palpation revealed that the renal masses resembled hydronephrosis. Direct punctures drew 450 ml. of pale urine from the right kidney and 390 from the left. On the tenth day cystotomy was performed; through the right ureteric orifice catheterization and even dye injection using the Chevassu catheter with expanded tip proved impossible because of total atresia of the intramural ureter; injection was possible through the left orifice, followed by forceful catheterization, and finally uretero-pyelography (Fig. 1). A side-to-side vesicoureteral anastomosis was performed on each side. A month later excision of the redundant pelvis and upper ureter was followed by uretero-pelvioplasty on the left side (Fig. 2); the renal parenchyma was barely $5 \mathrm{~mm}$. in thickness. A fortnight later, on the right side, the same condition was encountered and the same procedure performed, but the vascular pedicle was much too long. However, things went smoothly and on both sides a nephrostomy tube was left in situ in order to evaluate each subsequent recovery.

The right kidney became infected and had to be removed, but the left soon developed enough function to be able to sustain life (Fig. 3), and the nephrostomy was closed. Cystostomy had to be performed and maintained for a while because of sclerosis of the bladder neck; this was excised later on. Some time later a young assistant decided that the baby would be more comfortable if he tried to close the bladder, but it leaked, and during a further attempt at closure all the scar tissue was removed.

\footnotetext{
* A paper read at a meeting of the British Association.of Paediatric
} Surgeons in Sheffield, July 1963.
The bladder became almost the size of a nut and soon leaked again, and the cystostomy has, therefore, had to become permanent.

The child remained in good health, and check-ups were made from time to time. When he was 4 years old, urography showed fairly satisfactory renal function but the bladder remained very small with massive reflux. When he was $6 \frac{1}{2}$ (Fig. 4) his condition was almost the same, but bladder capacity had increased. It now seems possible to perform an anti-reflux procedure (Hutch's being the easiest and safest), and the bladder neck will be excised and cystostomy suppressed.

At 7 years (Fig. 5) blood urea is $28 \mathrm{mg}$. $/ \mathrm{ml}$.; urine is sterile with a specific gravity of 1004 to 1015 ; electrolytes and alkaline reserve are normal. The boy weighs 19.45 $\mathrm{kg}$. and is $1 \cdot 17 \mathrm{~m}$. in height.

Case 2. A 3-year-old girl had recurrent peaks of fever, cystitis and pyuria. At urography, bilateral multiple lithiasis was present; there were four to six stones in each

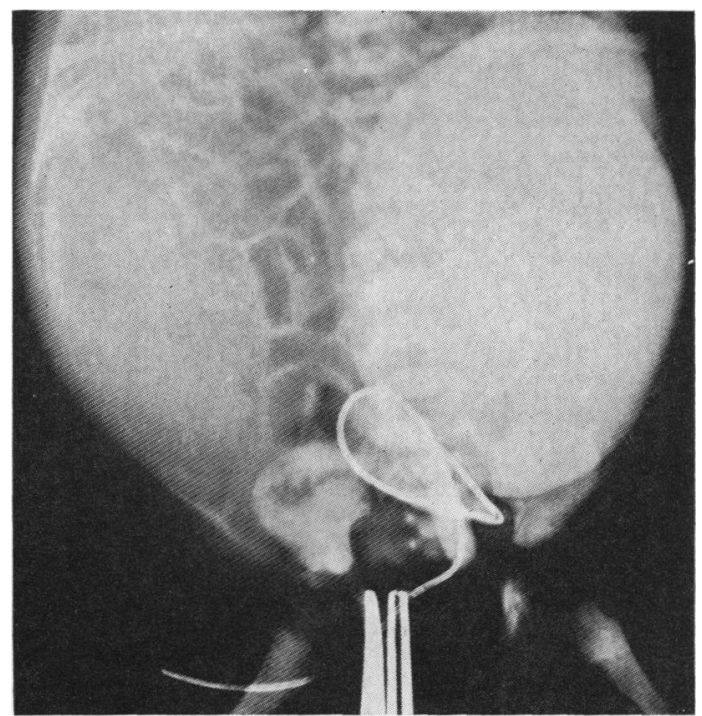

Fig. 1.-Case 1, 10 days old, after cystotomy. The forceps point to the ureteric orifices. The right one was impossible to catheterize, but the left one was possible. Uretero-pyelography on this side. 

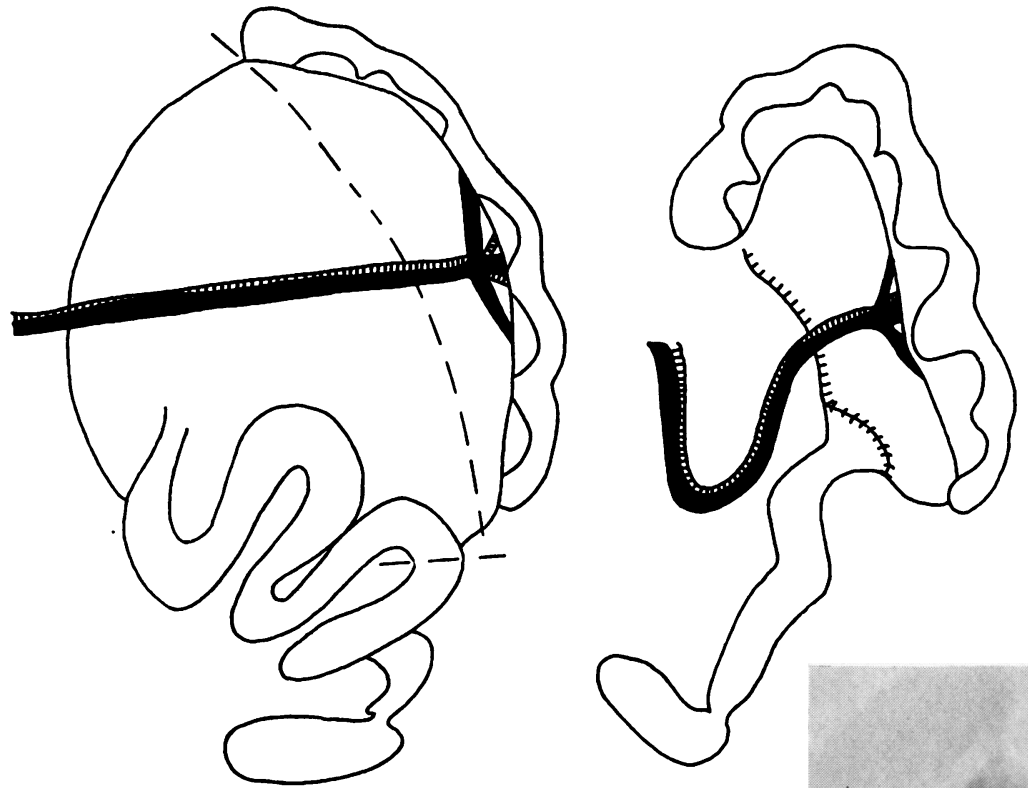

Fig. 2.-Case 1, 2 months of age, at operation. On the left side (almost the same as on the right) excision of redundant pelvis and upper ureter. Uretero-pelvioplasty. Vascular pedicle had become much too long.

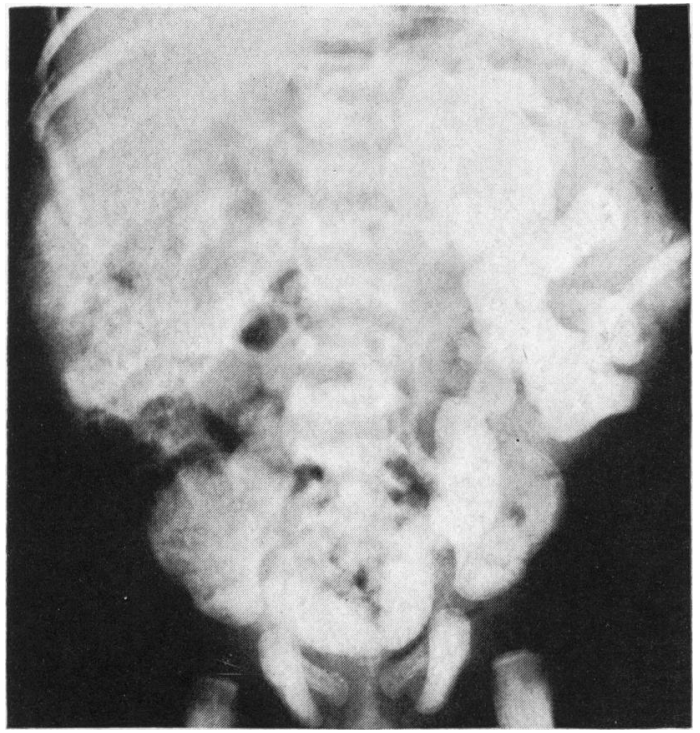

FIG. 3.-Case 1. Urography three months after operation shows the nephrostomy tubes still in situ but clipped by forceps. Right kidney almost silent after two hours and 20 minutes; good concentration of dye in the left kidney but free reflux from the bladder.

Fig. 4.-Case 1. Cystography at 6 years and 7 months showed massive reflux from the bladder which increased in size, and an antireflux procedure now seemed possible, as the boy was in excellent health. 

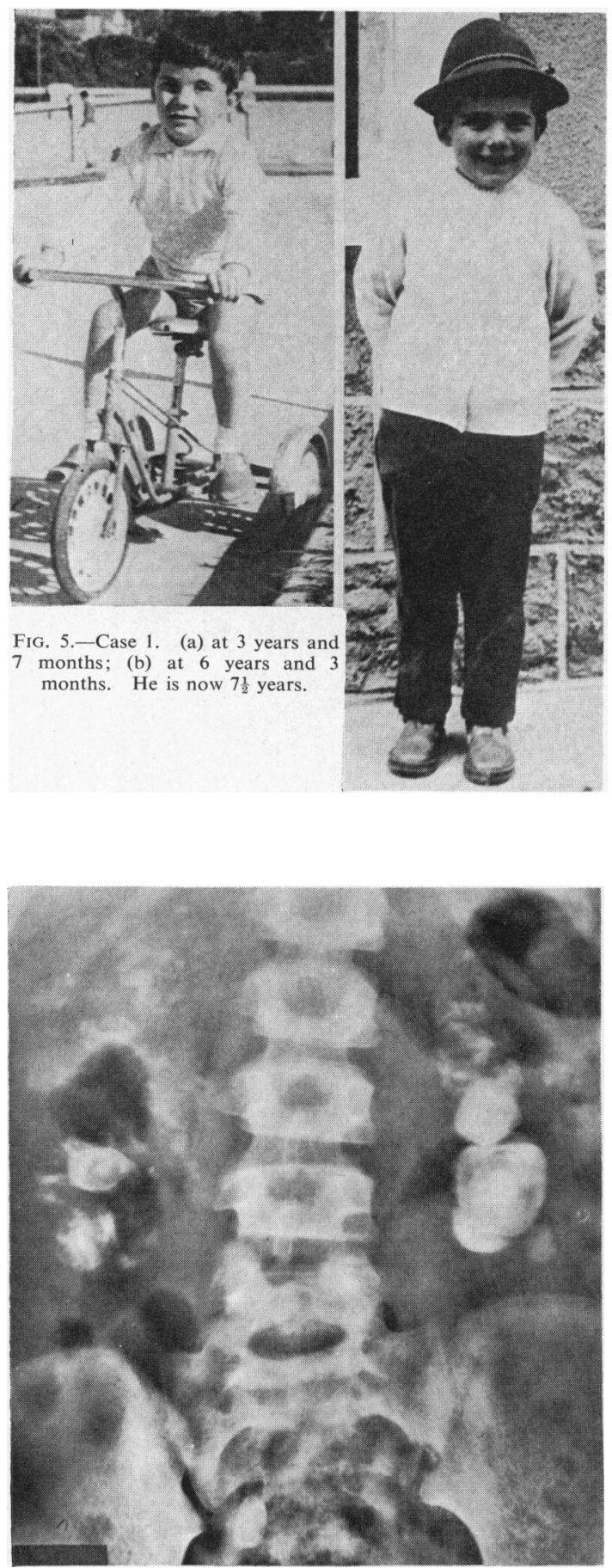

Fig. 6.-Case 2 at 7 years. Urography revealed multiple stones in both kidneys, together with gravel and sand. Poor renal function at the 20th minute. A 'stone' in the right pelvic ureter is perhaps an artefact for it had spontaneously disappeared one year later. kidney, together with gravel, sand, and poor renal function. The case was considered hopeless.

At the age of 7, as she was getting on all right in spite of recurrent urinary infection, urography was performed again (Fig. 6) in order to decide whether or not to remove the stones. There was little change from the preceding films except for a stone in the right ileo-pelvic ureter, which was thought to increase the difficulties of operation; radical treatment was, therefore, again abandoned.

At the age of 8 (1948) she was sent to me in a moribund condition suffering from bilateral pyonephrosis with huge tender renal masses, a temperature of $41^{\circ} \mathrm{C}$., blood urea of $115 \mathrm{mg} . / 100 \mathrm{ml}$.; leucocytes 36,000 . For three days penicillin had almost no effect (in those days only small doses were given: 200,000 units twice a day). It was replaced by sulphapyridine 2 g. i.m. twice a day, a high dose even for adults. Her general condition unexpectedly improved sufficiently for an operation to be performed. Her temperature was $37 \cdot 8^{\circ} \mathrm{C}$., blood urea $45 \mathrm{mg} . / 100 \mathrm{ml}$., and the kidneys returned to normal size under palpation. Amazingly enough the ureteral 'stone' (whether real or artefact) had totally disappeared.

Nephrolithotomy was carried out on the right kidney, the parenchyma of which was so thin that, were the condition unilateral, the organ would unquestionably have been removed. The complete removal of the stones, gravel and sand was easy, but the prognosis was apparently

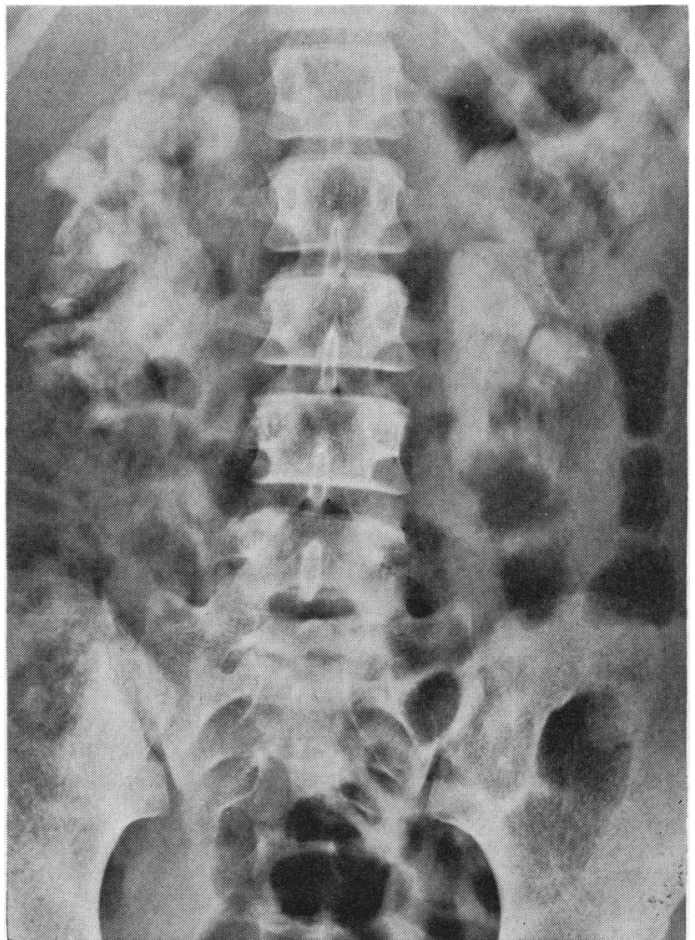

Fig. 7.-Urography of Case 2 , at 14 years, and six years after operation. Decompression at the 30th minute. There is fairly good renal function. 


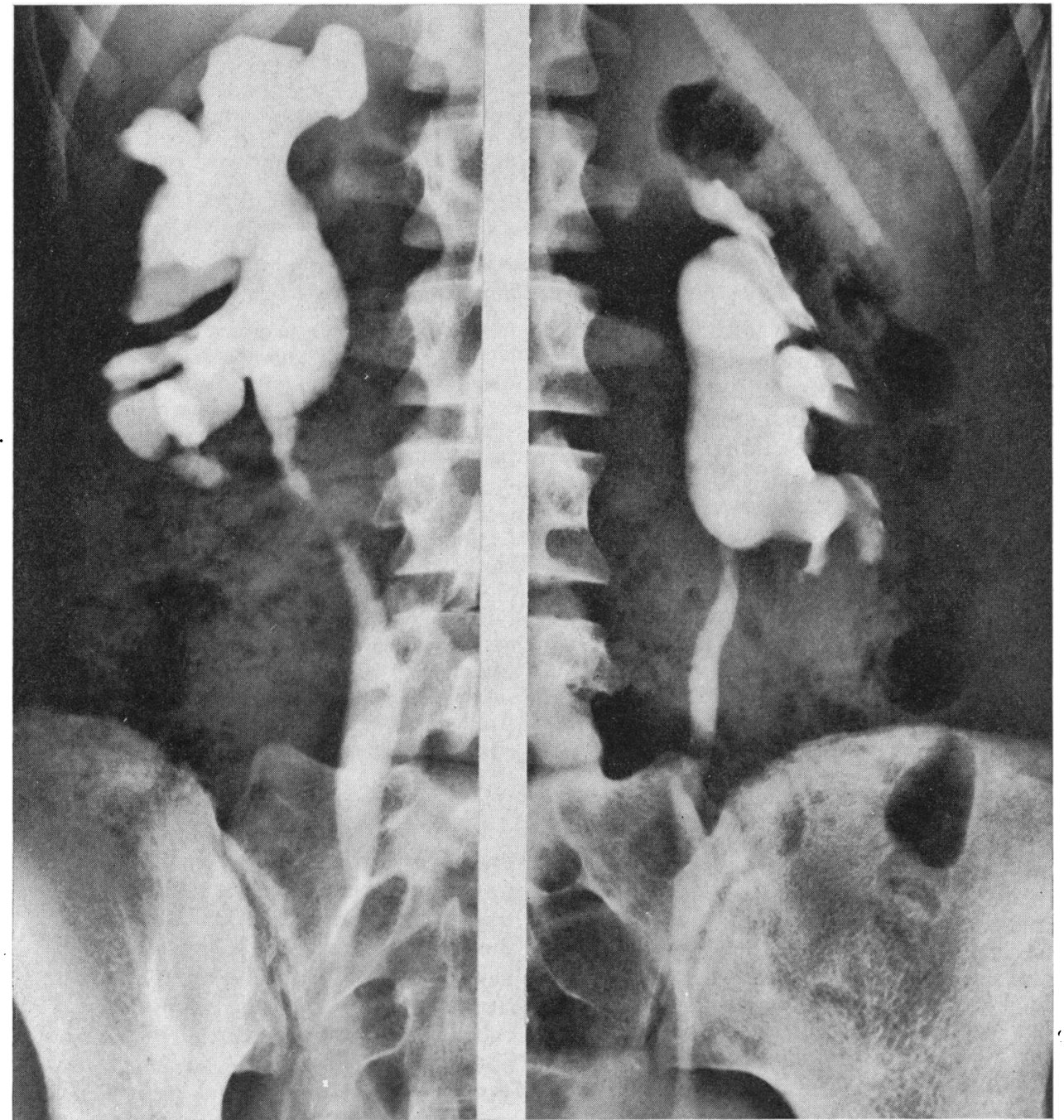

hopeless. A nephrostomy tube was left, and the kidney was closed with interrupted catgut sutures. Clear urine soon appeared through the tube, increasing in volume and specific gravity from 1002 to 1010 . Three weeks later, the same procedure was done with the left kidney with the same result.

Two years later the girl was still living and in good health. Urography showed fair concentration of dye in the kidneys and no recurrence of stones (Figs. 7, 8).
Some time later she fell in love with a third-rate painter and, despite her father's objections, she married. Now at the age of 23 she is the mother of three children and is still in good health with no recurience of stones: blood urea $38 \mathrm{mg}$./100 ml.; clear sterile urine with specific gravity from 1003 to 1022 ; electrolytes and alkaline reserve normal; phenosulfonphthalein $18 \%$ in 15 minutes, $30 \%$ in 35 minutes, $48 \%$ in 70 minutes. She is $5 \mathrm{ft} .8$ in. $(1 \cdot 70$ metres) in height and weighs only $121 \mathrm{lb} .(55 \mathrm{~kg}$.$) .$ 